\title{
HPLC Quantification of Phenolic Acids from Vetiveria zizanioides (L.) Nash and Its Antioxidant and Antimicrobial Activity
}

\author{
Jha Prajna, Jindal Richa, and Chakraborty Dipjyoti \\ Department of Bioscience and Biotechnology, Banasthali Vidyapith, Rajasthan 304022, India \\ Correspondence should be addressed to Chakraborty Dipjyoti; dciitkgp@gmail.com
}

Received 31 October 2012; Revised 31 January 2013; Accepted 31 January 2013

Academic Editor: Anna Wesolowska

Copyright ( 2013 Jha Prajna et al. This is an open access article distributed under the Creative Commons Attribution License, which permits unrestricted use, distribution, and reproduction in any medium, provided the original work is properly cited.

Extraction procedure was standardized and for the soluble, glycoside, and wall-bound fractions of phenolic acids from Vetiveria zizanioides. The water soluble alkaline extract which represents the cell wall-bound fraction contained the highest amount of phenolic acids (2.62 $\pm 1.2 \mu \mathrm{M} / \mathrm{g}$ fwt GA equivalents). Increased phenolic content in the cell wall indicates more lignin deposition which has an important role in plant defense and stress mitigation. Antioxidant property expressed as percentage TEAC value obtained by ABTS assay was correlated with the amount of phenolic acids and showed a Pearson's coefficient 0.988 (significant at 0.01 level). The compounds $p$-coumaric acid, $p$-dihydroxybenzoic acid, and ferulic acid were detected in the acidic extracts by HPLC analysis. The plant extracts exhibited considerable antimicrobial activity against tested bacterial and fungal strains.

\section{Introduction}

Natural products play a dominant role in pharmaceutical industry, and systematic investigation of natural resources for the discovery of new drug molecules is the primary objective for bioprospection programs [1]. There is about 127 natural products or natural-product-derived compounds currently undergoing clinical trials [2]. The common phenylpropanoid pathway is an essential pathway of secondary metabolism leading to a diverse range of compounds that are important both to the physiology of plants and to the many applications of plant natural products from lignin to pharmaceuticals and nutraceuticals $[3,4]$. Microbial resistance to antibiotics is a global concern covering all known classes of natural and synthetic compounds fueling the need for novel antimicrobials of which plants are a potent source [5-7].

Vetiveria zizanioides (L.) Nash (Poaceae), a perennial grass grows abundantly in the Gangetic plains of India and holds an esteemed place in the Indian mythology and traditional medicinal practices [8]. It is used as a relaxant for the nervous system, lowers heart rate, normalizes breathing, has anti-inflammatory properties, controls diabetes, and cures skin diseases [9]. The root decoction of the plant is used as an analgesic and, in inflammation, as an anthelmintic [10], antipyretic [11], and antioxidant [12], and as an antituberculosis agent [13]. The leaf juice is used as anthelmintic [14] and applied as paste for relief from rheumatism, lumbago, and sprain [15]. Cultivation of Vetiver grass has ecological advantages as it decreases soil erosion and is recommended in conservation studies [16]. Leaves of the plant are also used as raw material for handicraft making, mushroom cultivation, roof thatching, and several industrial products [17]. Although several bioactive compounds such as essential oils, stilbene derivatives, lipids, and phytosterols are reported from the plant [18], there is no information on phenolic compounds. Considering that the leaves provide more biomass as compared to the roots and can be regularly harvested, the present study aims to evaluate the antimicrobial activities of the leaf extracts with emphasis on phenolic compounds.

\section{Materials and Methods}

2.1. Plant Material. V.zizanioides plants used for the present study were collected from Darbhanga district, North Bihar, 
India and authenticated by Dr. V Jha, Department of Botany, CM Science College, Darbhanga, India.

2.2. Test Organisms. The bacterial strains Escherichia coli and Bacillus subtilis were obtained from IMTECH, Chandigarh, India. Micrococcus luteus was obtained from the Microbiology Laboratory, Banasthali Vidyapith, India. The fungal strains (Aspergillus niger, Fusarium oxysporum, and Macrophomina phaseolina) were obtained from the Plant Pathology Laboratory, Banasthali Vidyapith, India.

2.3. Chemicals. The phenolic acid standards, $p$-coumaric acid hydroxybenzoic acid, and ferulic acid were obtained from Fluka, Chemie GmBH. ABTS was obtained from Sigma Aldrich. HPLC-grade methanol and water were procured from Merck, India.

2.4. Extraction of Phenolic Acids. Extraction of phenolics was done for alcoholic (80\% methanol $(\mathrm{M}))$, acidic $(0.1 \mathrm{~N} \mathrm{HCl}$, water soluble (HW), methanol soluble (HM)), and alkaline $(1 \mathrm{~N} \mathrm{NaOH}$, water soluble (NW), methanol soluble (NM)) extracts following the previously published protocols [19-23]. In alcoholic extraction process, leaves $(1 \mathrm{~g})$ were crushed in $5 \mathrm{~mL}$ of $80 \%$ aqueous methanol, filtered, and centrifuged at $5000 \mathrm{rpm}$ for $10 \mathrm{~min}$. The supernatant was collected. For aqueous acidic extract, leaves $(1 \mathrm{~g})$ were boiled in $0.1 \mathrm{~N} \mathrm{HCL}$ for 25-30 min and filtered. The filtrate was then partitioned with ethyl acetate and dissolved in water (HW) and the portion insoluble in water dissolved in $80 \%$ methanol (HM). In the alkaline extraction process, leaves $(1 \mathrm{~g})$ were boiled in $0.1 \mathrm{~N} \mathrm{HCL}$ for $25-30 \mathrm{~min}$ and centrifuged at $5000 \mathrm{rpm}$ for $10 \mathrm{~min}$. The residue was kept in $1 \mathrm{~N} \mathrm{NaOH}(2 \mathrm{~mL})$ overnight. It was again centrifuged and the filtrate brought to $\mathrm{pH} 2$, partitioned ethyl acetate and dissolved in water (NW) and the portion insoluble in water dissolved in $80 \%$ methanol (NM).

2.5. Determination of Total Phenolic Content. Freshly harvested leaves were used for analysis. Total phenolics were determined with Folin-Ciocalteu reagent, which takes into account all hydroxylated aromatic compounds and expressed as gallic acid equivalents. The phenolic content was estimated by taking absorbance at $660 \mathrm{~nm}$ using a Systronics 2269 Spectrophotometer (Systronics, India) and expressed as gallic acid (GA) equivalents.

2.6. HPLC Analysis of Phenolic Acids. For quantitative estimation of phenolic acids, HPLC was performed using a RP C18 Whatman (UK) 5 ODS column $(25 \mathrm{~cm} \times 4.6 \mathrm{~mm})$ on a Shimadzu HPLC system (System Control SCL: 10A, Uvvis detector: SPD 10A, Pump: LC-10AT, Shimadzu, Japan) using a modified method of Sachan et al. [24]. The polar mobile phase comprised with methanol: aqueous $1 \mathrm{mM}$ of trifluoroacetic acid $30: 70$ at a flow rate of $1 \mathrm{~mL} \mathrm{~min}^{-1}$ for $20 \mathrm{~min}$ and the detector monitored at $254 \mathrm{~nm}$. To minimize variation in quantification, samples were taken in triplicate.

\subsection{Total Antioxidant Activity}

ABTS Assay. The ability of the test sample to scavenge ABTS+ radical cation was compared to trolox standard [25]. The percentage inhibition of absorbance on test sample on ABTS was calculated and plotted as a function of the concentration of standard and sample to determine the trolox equivalent antioxidant concentration (TEAC). All experiments were repeated three times.

2.8. Antibacterial Assay. Antibacterial activity of phenolic extracts was tested using broth dilution method following [26]. Briefly, an aliquot of individual bacterial stock was grown overnight at $37^{\circ} \mathrm{C}$ in $2 \mathrm{~mL}$ liquid $\mathrm{LB}$ medium for inoculation. Inoculum was added to culture medium supplemented with various concentrations $(100,200$, and $300 \mu \mathrm{L})$ of extract. Bacterial culture without extract was used as control and growth was measured at $540 \mathrm{~nm}$ after $24 \mathrm{~h}$. Kanamycin $(10 \mu \mathrm{g} / \mathrm{mL})$ was used as a positive standard in the assay.

2.9. Antifungal Assay. Phenolic acid extracts were added to Potato Dextrose Broth medium $(50 \mathrm{~mL})$ in conical flasks. The mycelia of fungal strains were transferred to the flasks and incubated at $37^{\circ} \mathrm{C}$. When the fungal mycelium reached the edge of the control flask, the dry weight was determined by filtering and drying in an oven at $50^{\circ} \mathrm{C}$. Bavistin was used as a positive standard in the assay. Antifungal index was calculated by the formula:

$$
\text { Antifungal index }(\mathrm{AI} \%)=1-\left(\frac{\mathrm{W}_{\mathrm{a}}}{\mathrm{W}_{\mathrm{b}}}\right) * 100 \text {, }
$$

where $\mathrm{W}_{\mathrm{a}}$ is the weight of the fungal mycelia in the experimental set and $\mathrm{W}_{\mathrm{b}}$ is the weight of the mycelium in control set.

2.10. Statistical Analysis. A randomized block design was used to set up all the experiments. Data were examined by analysis of variance (ANOVA) to detect the differences $(P=$ 0.05 ) between the means and compared using Tukey's HSD test at the same (5\%) probability level using SPSS software (ver. 17.0.0; SPSS, Chicago, IL, USA). LC $_{50}$ values were computed by Probit analysis in R-Software ( $\mathrm{R}$ version 2.9.0, The R Foundation for Statistical Computing, 2009). Correlation between phenolic content and antioxidant value was done by Pearson's coefficient.

\section{Results and Discussion}

The aim of the present work is to standardize extraction procedures for phenolic acids from $V$. zizanioides and investigate its antioxidant and antimicrobial activity.

The concentrations of total phenolics and the antioxidant property of the different fractions of plant extracts are represented in Table 1. It was observed that the phenolic content varied according to the extraction procedure for optimum release of the metabolites from the leaf matrix. Alcohols (methanol, ethanol) are frequently used to extract phenolic 
TABLE 1: Total phenolics and antioxidant values of different fractions of $V$. zizanioides leaves.

\begin{tabular}{lcc}
\hline Phenolic fraction & $\begin{array}{c}\text { Total phenolics* } \\
(\text { GA equivalent } \\
\mu \mathrm{M} / \mathrm{g} \text { fwt })\end{array}$ & $\begin{array}{c}\text { Antioxidant } \\
\text { property } \\
\text { TEAC value (\%) }\end{array}$ \\
\hline HW & $2.03 \pm 0.9^{\mathrm{b}}$ & 54.73 \\
$\mathrm{HM}$ & $0.97 \pm 0.4^{\mathrm{a}}$ & 21.45 \\
$\mathrm{NW}$ & $2.62 \pm 1.7^{\mathrm{c}}$ & 65.2 \\
$\mathrm{NM}$ & $1.09 \pm 0.5^{\mathrm{a}}$ & 26.63 \\
$\mathrm{M}$ & $1.19 \pm 0.5^{\mathrm{a}}$ & 30.04 \\
\hline
\end{tabular}

*Values are mean \pm standard error. Means followed by the same letter in a column are not significantly different at $P=0.05$ according to analysis of variance and Tukey's HSD test.

HW: water soluble acidic fraction, HM: methanol soluble acidic fraction, NW: water soluble alkaline fraction, NM: methanol soluble alkaline fraction, and M: $80 \%$ methanolic extract.

compounds from plant material $[19,20]$. In V. zizanioides, higher amounts of phenolic acids were extracted by the acidic and alkaline extraction procedure as compared to methanolic extraction indicating the presence of glycoconjugates. Saponification of the residue left after acidic extraction with $\mathrm{NaOH}$ (NM and NW) that releases cell wall-bound compounds resulted in highest yield of total phenolics in $V$. zizanioides. Several simple phenylpropanoids (with basic C6-C3 carbon skeleton) are rarely found in the free form in plant cells and are generally conjugated to sugars, cell wall carbohydrates, or organic acids [21,22]. The presence of such conjugates leads to extraction of higher amount of phenolic acids on acid/alkali treatment. Plant matrices behave differentially to extraction solvents for phenolic acids, and a compound may not form the same conjugate in another species necessitating standardization of optimum extraction procedure [23].

HPLC analysis of the acidic extract showed eight peaks (Figure 1) out of which three were identified as $p$-hydroxybenzoic acid $\left(R_{t} 8.34 \mathrm{~min}, 5.58 \mu \mathrm{g} / \mathrm{g}\right.$ fresh weight), $p$ coumaric acid $\left(R_{t} 15.83,13.2 \mu \mathrm{g} / \mathrm{g}\right.$ fresh weight), and ferulic acid $\left(R_{t} 18.608,14.17 \mu \mathrm{g} / \mathrm{g}\right.$ fresh weight). $R_{t}$ 's of the peaks that were not identified are as follows: $4.13,4.93,6.57,9.13$, and 16.95. Hydroxycinnamates such as $p$-coumaric acid are major components of plant cell walls, particularly of monocots and are esterified with lignin — a key cell wall component $[27,28]$. Hydroxybenzoides have widespread application in food and pharmaceutical industry [29] and are also important intermediates in synthesis of fragrance and flavor compounds in plants [30]. Recently, it was shown that certain rot fungi have the capacity to convert $p$-coumaric to $p$-hydroxybenzoic acid [31] which has considerable ecophysiological and commercial implications. Ferulic acid has an important role in plant cell wall formation [32] and is an effective antioxidant [33] and anticancer compound [34]. Commercially ferulic acid is synthesized from petroleum. There are few commercially viable biological sources of ferulic acid such as rice barn [35], and $V$.zizanioides might offer a cost effective alternative.

The alkaline water soluble extract, which pertains to the cell wall component of $V$. zizanioides, had the highest antioxidant value expressed as percentage TEAC (Table 1). Pearson's correlation coefficient value was found to be 0.988 (significant at $P=0.01$ ) indicating that phenolic acids present in the different fractions highly correlate with the TEAC values. Thus, antioxidant property of the extracts can be attributed to the presence of phenolic acids. Vetiver oil is reported to possess a strong free radical scavenging activity when compared to standard antioxidants such as butylated hydroxytoluene (BHT) and $\alpha$-tocopherol [36]. High antioxidant potential of the hexane extracts obtained from roots of Vetiver grass is also reported [37].

The antibacterial activity of the plant extracts is represented in Figure 2. Initially the crude phenolic extracts were tested for their effectiveness against the bacterial strains in agar plate assay (results not shown). The quantification of antibacterial activity was done by broth assay method. In general, the extracts were more potent against the gram negative E. coli in comparison to B. subtilis and M. luteus, except for the alkaline methanol soluble fraction which was more potent against $M$. luteus and the methanol soluble acid extract which was more active against $B$. subtilis. The water soluble and methanol soluble alkaline extract showed the lowest $\mathrm{LC}_{50}$ values hence highest activity against $E$. coli. Alkaline extract dissolved in methanol showed highest activity against $B$. subtilis and $M$. luteus. The $\mathrm{LC}_{50}$ values of Kanamycin against $E$. coli, B. subtilis, and M. luteus were 146.36, 121.18 , and $45.42 \mu \mathrm{g} / \mathrm{mL}$, respectively.

The water soluble alkaline fraction contained the highest amount of phenolic acids and it was the most effective against the B. subtilis and M. luteus; however, the methanolic fraction although contains lower amount of phenolic acid is more effective against $E$. coli in comparison to the other extracts. The lowest concentration of phenolic acid was extracted in the methanol soluble acidic fraction, but the minimum activity was shown by the methanol soluble alkaline fraction, indicating the importance of the type of phenolic acids to be more important for activity rather than the amount. The methanol soluble alkaline fraction was also less active against gram positive bacteria as compared to gram negative bacteria, a feature which is not observed in the other extracts except for methanol soluble acidic fraction. The wide variation in the activity of different phenolic extracts of the same plant species indicates the variation of the phenolic constituents extracted from the plant matrix by acidic, alkaline, and alcoholic extraction procedures.

The antifungal activity was calculated as antifungal index with shows the percentage of growth inhibition of the fungi (Table 2). In contrary to the antimicrobial activity, the methanol soluble alkaline fraction consistently showed better antifungal activity against $A$. niger and $M$. phaseolina. The water soluble acidic fraction and the methanolic fraction were more effective against $F$. oxysporum although the content of total phenolics of methanol soluble alkaline fraction is lower than the water soluble acidic fraction.

Similarly, although the total phenolic content of the methanol soluble acidic fraction is lowest among all the extracts, it shows potent antifungal activity against all the fungal strains tested in contrast to the water soluble acidic fraction which is less effective against $A$. niger and 


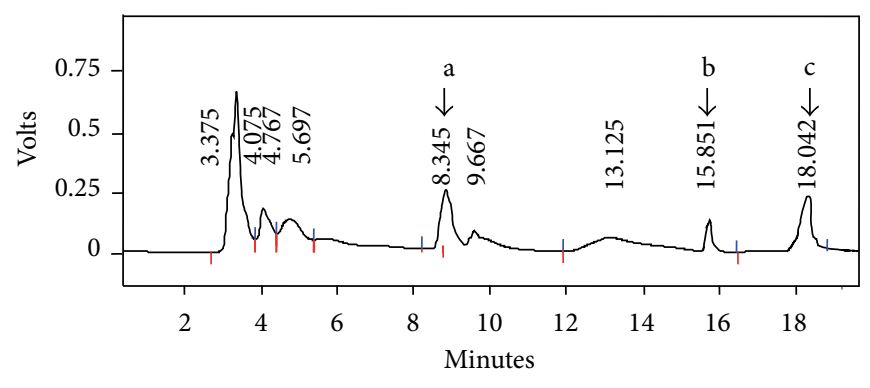

— Detector A (254 $\mathrm{nm})$ retention time

FIGURE 1: HPLC chromatogram of the phenolic acids (acidic fraction) from $V$. zizanioides leaves. The values represent retention time $\left(R_{t}\right)$ in min. a: $p$ hydroxybenzoic acid, b: $p$ coumaric acid, and c: ferulic acid.

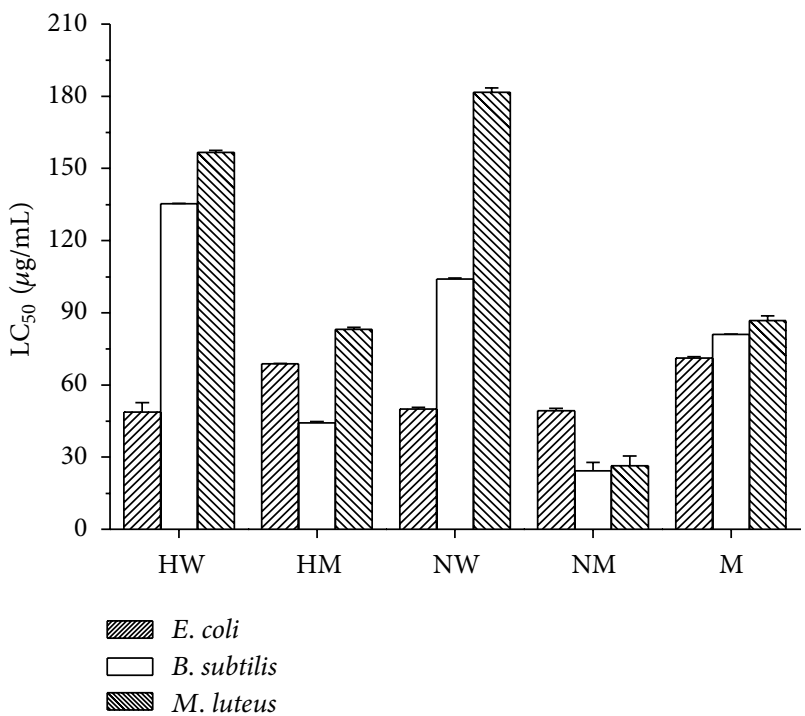

FIgURE 2: Antibacterial activity ( $\mathrm{LC}_{50}$ values) of the phenolic extracts of $V$.zizanioides against the bacterial strains E. coli, B. subtilis, and M. luteus. HW: water soluble acidic fraction, HM: methanol soluble acidic fraction, NW: water soluble alkaline fraction, NM: methanol soluble alkaline fraction, and M: $80 \%$ methanolic extract.

M. phaseolina. It is, thus, evident that a simple correlation between the total phenolic content and its antibacterial/antifungal activity cannot be drawn, rather the individual constituents of phenolic acids and their concentration variation have to be taken into consideration.

The antimicrobial activity observed in vitro against the three bacterial and three fungal strains could be attributed to the presence of polyphenolic compounds in the Vetiveria extracts. It is postulated that the antibacterial properties of phenolic acid are due to nucleoid damage with an increase in spatial division and condensation of genetic material [26]. Phenolic acids exhibit strong antibacterial property against gram positive bacteria and partial inhibition of gram-negative bacteria $[26,38]$. In the present study, higher inhibition of gram negative E. coli was observed. An earlier
TABle 2: Antifungal activity (antifungal index) of the phenolic extracts of $V$. zizanioides against the fungal strains A. niger, $F$. oxysporum, and M. phaseolina.

\begin{tabular}{lccc}
\hline Phenolic & \multicolumn{3}{c}{ Antifungal index* $\left.{ }^{*} \%\right)$} \\
fractions & A. niger & F. oxysporum $^{\mathrm{M}}$ & M. phaseolina \\
\hline HW & $62.86 \pm 1.65^{\mathrm{ab}}$ & $64.79 \pm 1.49^{\mathrm{d}}$ & $67.11 \pm 0.58^{\mathrm{c}}$ \\
$\mathrm{HM}$ & $77.04 \pm 0.46^{\mathrm{d}}$ & $60.86 \pm 0.66^{\mathrm{c}}$ & $63.40 \pm 0.88^{\mathrm{bc}}$ \\
NW & $60.99 \pm 0.98^{\mathrm{a}}$ & $56.38 \pm 1.31^{\mathrm{b}}$ & $61.82 \pm 1.95^{\mathrm{b}}$ \\
NM & $81.20 \pm 1.28^{\mathrm{e}}$ & $59.89 \pm 1.68^{\mathrm{bc}}$ & $75.17 \pm 0.91^{\mathrm{d}}$ \\
M & $64.95 \pm 0.81^{\mathrm{b}}$ & $63.05 \pm 1.12^{\mathrm{cd}}$ & $71.80 \pm 2.61^{\mathrm{d}}$ \\
Bavistin & $71.26 \pm 0.32^{\mathrm{c}}$ & $38.77 \pm 1.13^{\mathrm{a}}$ & $52.24 \pm 1.05^{\mathrm{a}}$ \\
\hline
\end{tabular}

*Values are mean \pm standard error. Means followed by the same letter in a column are not significantly different at $P=0.05$ according to analysis of variance and Tukey's HSD test.

HW: water soluble acidic fraction, HM: methanol soluble acidic fraction, NW: water soluble alkaline fraction, NM: methanol soluble alkaline fraction, and M: $80 \%$ methanolic extract.

study on Vetiver oil also reported high antibacterial activity against drug resistant strains of E. coli [37]. The antifungal activity of polyphenolic compounds is reported to be due to the formation of multinucleate stage by the breakage of intersepta in the mycelium and cell surface damage by pilferage [26].

Most of the antimicrobial drugs, particularly the antimycotic drugs, have several limitations such as low potency, poor solubility, emergence of resistant strains, and drug toxicity and have to be phased out with time [39]. As such, the search for new antimicrobial agents is necessary to stimulate the research of new therapeutic agents from medicinal plants. The present study also assumes importance as growth-promoting antibiotics in animal feeds are banned in European countries [40]. The detection of antioxidant property in $V$. zizanioides also indicates that it could be used in food supplements and nutraceuticals. There is increasing interest in using natural products including probiotics, prebiotics, enzymes, organic acids, and secondary plant metabolites or their nature-identical chemicals that do not pose a public health hazard as feed additives to solve problems in animal nutrition and livestock production and in future human diet. 


\section{Acknowledgments}

The authors thank Professor Aditya Shastri, Vice Chancellor, Banasthali Vidyapith, India for providing the necessary facilities. The authors thank DST, Government of India for providing instruments under the CURIE Program to Banasthali Vidyapith.

\section{References}

[1] W. P. Jones, Y. Chin, and A. D. Kinghorn, "The role of pharmacognosy in modern medicine and pharmacy," Current Drug Targets, vol. 7, no. 3, pp. 247-264, 2006.

[2] A. Harvey, "Natural products in drug discovery and development," Drugs, vol. 8, no. 9, pp. 719-721, 2005.

[3] S. M. Mandal, D. Chakraborty, and S. Dey, "Phenolic acids act as signaling molecules in plant-microbe symbioses," Plant Signaling \& Behavior, vol. 5, no. 4, pp. 359-368, 2010.

[4] R. A. Dixon, "Engineering of plant natural product pathways," Current Opinion in Plant Biology, vol. 8, no. 3, pp. 329-336, 2005.

[5] H. Adcock, "Pharmageddon: is it too late to tackle growing resistance to anti-infectives?” Pharmaceutical Journal, vol. 269, pp. 599-600, 2002.

[6] J. Clardy and C. Walsh, "Lessons from natural molecules," Nature, vol. 432, no. 7019, pp. 829-837, 2004.

[7] V. M. D'Costa, K. M. McGrann, D. W. Hughes, and G. D. Wright, "Sampling the antibiotic resistome," Science, vol. 311, no. 5759, pp. 374-377, 2006.

[8] R. R. Rao and M. R. Suseela, "Vetiveria zizanioides (Linn.) Nash-a multipurpose eco-friendly grass of India," in Proceedings of the 3rd International Vetiver Conference, Thailand, January 2000.

[9] N. S. Chia, "Ethnopharmacology and Pharmacological properties of Vetiveria zizanioides," in Vetiveria, M. Maffei, Ed., pp. 4572, Taylor \& Francis, New York, NY, USA, 2002.

[10] S. K. Karan, D. K. Pal, D. K. Tarai, and S. K. Mishra, "Analgesic and anthelmintic activity of Vertiveria zizanioides root," Journal of Pharmacy Research, vol. 3, pp. 893-894, 2010.

[11] M. B. Narkhede, P. V. Ajmire, A. E. Wagh, M. R. Bhise, G. D. Mehetre, and H. J. Patil, "An evaluation of antipyretic potential of Vetiveria zizanioides (Linn.) root," Research Journal of Pharmacognosy and Phytochemistry, vol. 4, no. 1, pp. 11-18, 2012.

[12] S. Luqman, S. Srivastava, M. P. Darokar, and S. P. S. Khanuja, "Detection of antibacterial activity in spent roots of two genotypes of aromatic grass Vetiveria zizanioides," Pharmaceutical Biology, vol. 43, no. 8, pp. 732-736, 2005.

[13] D. Saikia, S. Parveen, V. Gupta, and S. Luqman, "Anti-tuberculosis activity of Indian grass KHUS (Vetiveria zizanioides L. Nash)," Complementary Therapies in Medicine, vol. 20, no. 6, pp. 434-436, 2012.

[14] S. Mitra, V. K. Garg, S. K. Chaudhary, and J. K. Arya, "Pharmacognostical and phytochemical analysis of Vetiveria zizanioides (KHUS GRASS)," The Global Journal of Pharmaceutical Research, vol. 1, no. 3, pp. 311-317, 2012.

[15] S. Luqman, R. Kumar, S. Kaushik, S. Srivastava, M. P. Darokar, and S. P. S. Khanuja, "Antioxidant potential of the root of Vetiveria zizanioides (L.) Nash," Indian Journal of Biochemistry and Biophysics, vol. 46, no. 1, pp. 122-125, 2009.

[16] J. C. Greenfield, Vetiver Grass: An Essential Grass For the Conservation of Planet Earth, Infinity Publishing, Haverford, Pa, USA, 2002.
[17] N. Chomchalow, "The utilization of Vetiver as medicinal and aromatic plants," Pacific Rim Vetiver Network Technical Bulletin No. 2001/1.

[18] A. Akhila and M. Rani, "Chemical constituents and essential oil biogenesis in Vetiveria zizanioides," in Vetiveria, M. Maffei, Ed., pp. 73-109, Taylor \& Francis, New York, NY, USA, 2002.

[19] J. B. Harborne, Phytochemical Methods, Chapman \& Hall, London, UK, 1998.

[20] A. Ziaková and E. Brandšteterová, "Application of different preparation techniques for extraction of phenolic antioxidants from lemon balm (Melissa officinalis) before HPLC analysis," Journal of Liquid Chromatography and Related Technologies, vol. 25, no. 19, pp. 3017-3032, 2002.

[21] M. Kosar, H. J. D. Dorman, and R. Hiltunen, "Effect of an acid treatment on the phytochemical and antioxidant characteristics of extracts from selected Lamiaceae species," Food Chemistry, vol. 91, no. 3, pp. 525-533, 2005.

[22] D. Chakraborty and S. M. Mandal, "Fractional changes in phenolic acids composition in root nodules of Arachis hypogaea L.," Plant Growth Regulation, vol. 55, no. 3, pp. 159-163, 2008.

[23] D. Chakraborty, S. M. Mandal, J. Chakraborty et al., "Antimicrobial activity of leaf extract of Basilicum polystachyon (L) Moench," Indian Journal of Experimental Biology, vol. 45, no. 8, pp. 744-748, 2007.

[24] A. Sachan, S. Ghosh, and A. Mitra, "An efficient isocratic separation of hydroxycinnamates and their corresponding benzoates from microbial and plant sources by HPLC," Biotechnology and Applied Biochemistry, vol. 40, no. 2, pp. 197-200, 2004.

[25] R. Re, N. Pellegrini, A. Proteggente, A. Pannala, M. Yang, and C. Rice-Evans, "Antioxidant activity applying an improved ABTS radical cation decolorization assay," Free Radical Biology and Medicine, vol. 26, no. 9-10, pp. 1231-1237, 1999.

[26] H. P. Bais, T. S. Walker, H. P. Schweizer, and J. M. Vivanco, "Root specific elicitation and antimicrobial activity of rosmarinic acid in hairy root cultures of Ocimum basilicum," Plant Physiology and Biochemistry, vol. 40, no. 11, pp. 983-995, 2002.

[27] C. B. Faulds and G. Williamson, "A major bioactive component of plant cell walls, ferulic acid, influences feruloyl esterase production in Aspergillus niger," Biochemical Society Transactions, vol. 24, no. 3, p. 386, 1996.

[28] J. W. MacAdam and J. H. Grabber, "Relationship of growth cessation with the formation of diferulate cross-links and pcoumaroylated lignins in tall fescue leaf blades," Planta, vol. 215, no. 5, pp. 785-793, 2002.

[29] M. C. Wildermuth, "Variations on a theme: synthesis and modification of plant benzoic acids," Current Opinion in Plant Biology, vol. 9, no. 3, pp. 288-296, 2006.

[30] D. Chakraborty, D. Sircar, and A. Mitra, "Phenylalanine ammonia-lyase-mediated biosynthesis of 2-hydroxy-4-methoxybenzaldehyde in roots of Hemidesmus indicus," Journal of Plant Physiology, vol. 165, no. 10, pp. 1033-1040, 2008.

[31] A. Sachan, S. Ghosh, and A. Mitra, “Transforming p-coumaric acid into $p$-hydroxybenzoic acid by the mycelial culture of a white rot fungus Schizophyllum commune," African Journal of Microbiology Research, vol. 4, no. 4, pp. 267-273, 2010.

[32] A. Renger and H. Steinhart, "Ferulic acid dehydrodimers as structural elements in cereal dietary fibre," European Food Research and Technology, vol. 211, no. 6, pp. 422-428, 2000.

[33] F. Natella, M. Nardini, M. Di Felice, and C. Scaccini, "Benzoic and cinnamic acid derivatives as antioxidants: structure- activity relation," Journal of Agricultural and Food Chemistry, vol. 47, no. 4, pp. 1453-1459, 1999. 
[34] A. S. Meyer, J. L. Donovan, D. A. Pearson, A. L. Waterhouse, and E. N. Frankel, "Fruit hydroxycinnamic acids inhibit human lowdensity lipoprotein oxidation in vitro," Journal of Agricultural and Food Chemistry, vol. 46, no. 5, pp. 1783-1787, 1998.

[35] H. Taniguchi, E. Nomura, T. Tsuno, S. Mimami, K. Kato, and C. Hayashi, "Method of manufacturing ferulic acid. US Patent No. 5,288,902," Japanese Patent No. 2095088, 1994.

[36] H. Kim, F. Chen, W. Xi, Y. C. Hau, and Z. Jin, "Evaluation of antioxidant activity of vetiver (Vetiveria zizanioides L.) oil and identification of its antioxidant constituents," Journal of Agricultural and Food Chemistry, vol. 53, no. 20, pp. 7691-7695, 2005.

[37] S. Luqman, S. Srivastava, M. P. Darokar, and S. P. S. Khanuja, "Detection of antibacterial activity in spent roots of two genotypes of aromatic grass Vetiveria zizanioides," Pharmaceutical Biology, vol. 43, no. 8, pp. 732-736, 2005.

[38] A. M. Aljadi and K. M. Yusoff, "Isolation and identification of phenolic acids in Malaysian honey with antibacterial properties," Turkish Journal of Medical Sciences, vol. 33, no. 4, pp. 229236, 2003.

[39] G. Bisignano, A. Tomaino, R. Lo Cascio, G. Crisafi, N. Uccella, and A. Saija, "On the in vitro antimicrobial activity of oleuropein and hydroxytyrosol," Journal of Pharmacy and Pharmacology, vol. 51, no. 8, pp. 971-974, 1999.

[40] H. Greathead, "Plants and plant extracts for improving animal productivity," Proceedings of the Nutrition Society, vol. 62, no. 2, pp. 279-290, 2003. 

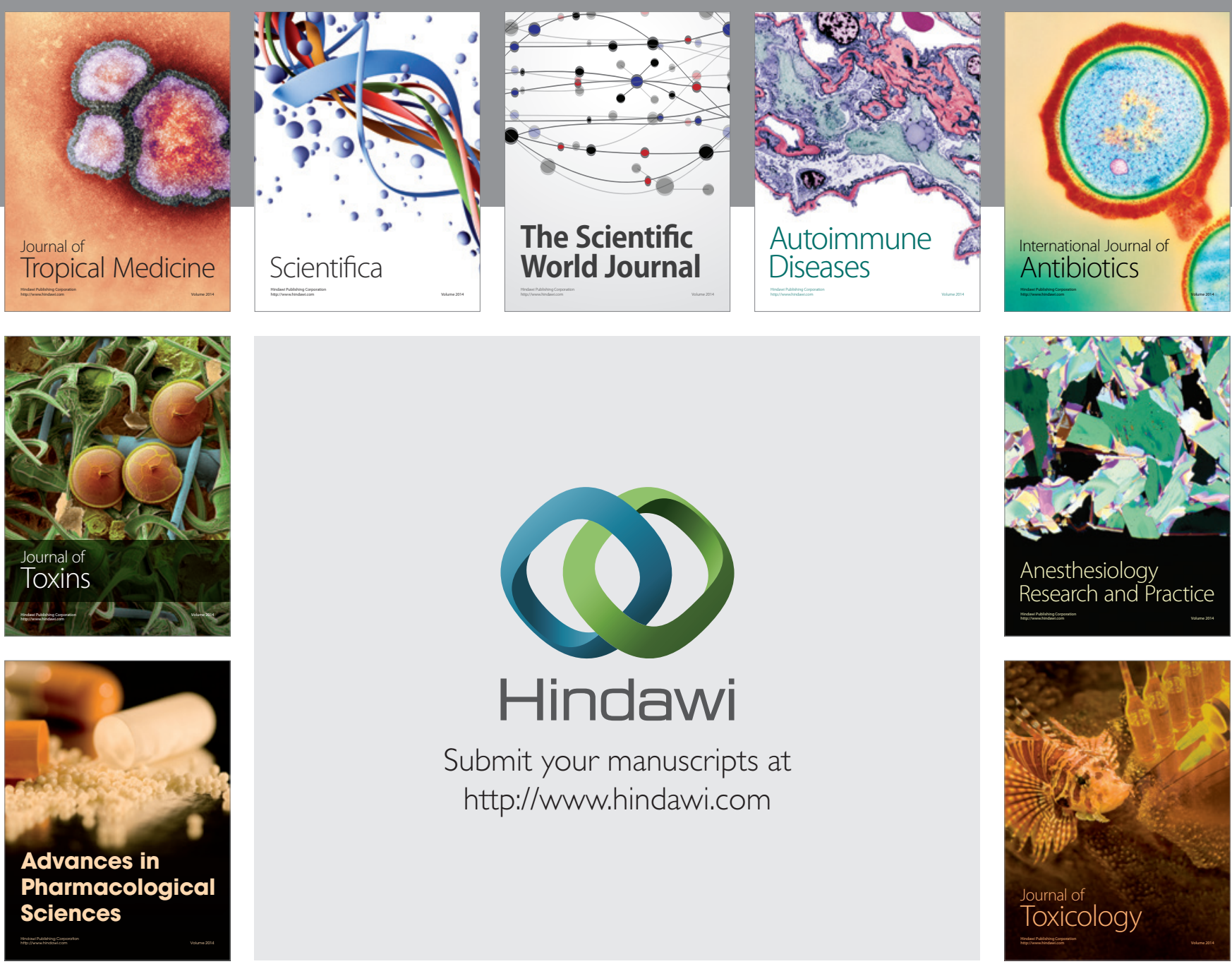

\section{Hindawi}

Submit your manuscripts at

http://www.hindawi.com
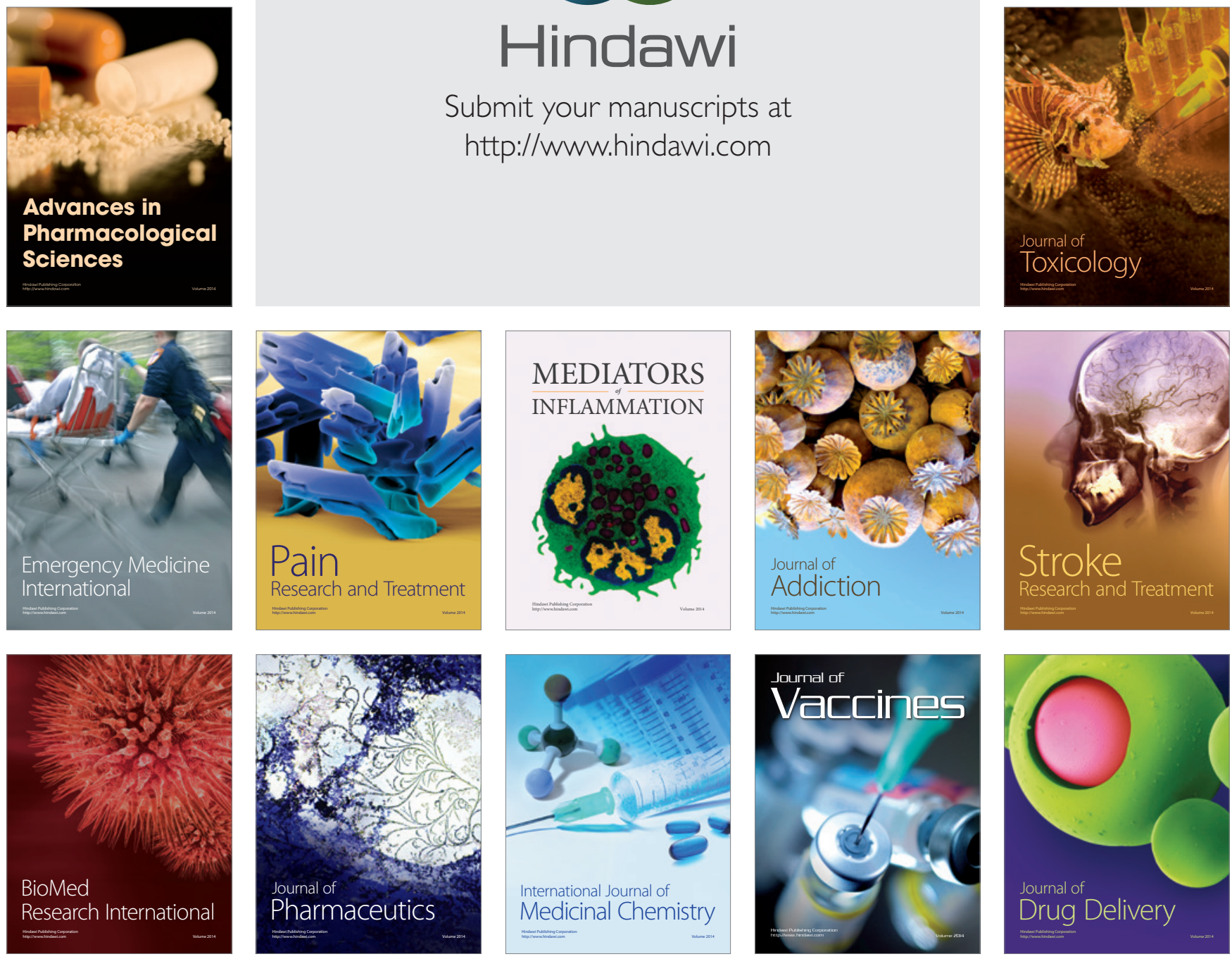